\title{
Wind Power Plants for Low Rated Wind Speed Regions: Feasibility Analysis and Simulation of a System
}

\author{
Mehmet Numan Kaya ${ }^{1, a}$ and Faruk Köse ${ }^{2}$ \\ ${ }^{1}$ Karamanoglu Mehmetbey University, Mechanical Engineering Department, Karaman, Turkey \\ ${ }^{2}$ Selcuk University, Mechanical Engineering Department, Konya, Turkey
}

\begin{abstract}
The use of wind power has become an important and growing part of the electrical energy supply in many countries all over the world. Wind turbines are the main components of wind power stations and every single development on these turbines affects the market. Latest developments in wind turbine technologies caused to decrease in costs, thus, besides high-wind-speed regions, low-wind-speed regions are taken into account as a feasible option to generate electricity. The present work investigates the feasibility of a wind power station located in a low rated wind speed region of Turkey providing a general approach for selection of the suitable wind turbine. Economic analysis was performed by calculating the key financial figures such as net present value (NPV), basic payback period (BPP) and the internal rate of return (IRR) for five various options and hourly mean, monthly and seasonal power productions are simulated for the most feasible option using the wind speed measurements in the region. Results show that it is possible to obtain a reasonable capacity factor in low rated wind speed regions with wind turbines that have larger rotors. Although the average wind speed is low in the examined region, a wind power station is still found to be feasible. According to the simulation results, maximum power is produced during the evening hours on a daily basis and during the summer months on a seasonal basis, ensuring power flow usually when maximum power consumption levels are reached. All the data used in this study are based on long-term measurements.
\end{abstract}

\section{Introduction}

Energy has been an essential component of human being since decades to perform various works and the need for energy will never end. Not harming the environment while producing energy is on the front burner of many researchers since people realized that environmental effects has the potential of negatively impacting the daily lives of individuals. The first thing that spring to mind is renewable energy when the topic is sustainable energy production. Today, most of the developed and developing countries are planning to increase energy production from renewables since these are environment friendly, native and unlimited. Wind power is one of the most known renewables and the use of wind to produce energy increases day by day. Global cumulative installed wind power capacity has increased from 17,400 to $432,419 \mathrm{MW}$ from 2000 to 2015 [1]. Studies on wind energy, especially about feasibility of wind power, have effect on the increase. In a feasibility study for İzmir, Turkey, authors stated that the larger the installed capacity, the smaller the generating cost per $\mathrm{kWh}$ and the higher IRR of the investment [2]. Another study for Turkey investigated the competition potential of wind power plants and it was concluded that the Marmara, southeast Anatolian and Aegean regions are highly suitable for wind power generation since wind speeds exceed $3 \mathrm{~m} / \mathrm{s}$ in most of these areas [3]. Shaahid et al. investigated economic feasibility of $75 \mathrm{MW}$ wind power plants on four coastal locations - Al-Wajh, Jeddah, Yanbu and Jizan - of Saudi Arabia and found out that capacity factors and unit costs vary from $12 \%$ to $21 \%$ and from 0.0423 to $0.0711 \mathrm{US} \$ / \mathrm{kWh}$, respectively [4]. Khabit et al. studied on Assessment of electricity generation by wind power in nine costal sites in Malaysia specified that average unit cost of the energy produced by a wind power system in Malaysia is 1.6-7.29 USD/kWh and the use of wind power systems as standalone systems is not recommended for the selected sites [5]. Celik pointed out in his study that the cost of wind electricity per $\mathrm{kWh}$ can be significantly reduced if the components of wind energy systems were exempted from taxes and subsidies were introduced [6]. Mostafaeipou et al. studied on wind energy feasibility study for city of Shahrbabak in Iran and recommended to install small size wind turbines for electricity supply of public buildings and private houses [7]. Blackler and Iqbal specified that a wind farm project at the Holyrood thermal generation station site is feasible in their study on Pre-feasibility study of wind power generation in Holyrood, Newfoundland [8]. Many other studies can be found in the literature

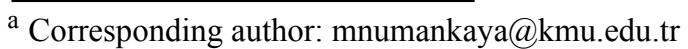


on feasibility of wind power plants [9-13], in addition, there are some review studies available for some countries [14-15].

The present study investigates the feasibility of a wind power station located in a low rated wind speed region of Turkey. Most proper wind turbine among various options is selected the for the region considering the low rated wind speed and it is simulated for different time periods. In addition, economic analysis was performed by calculating BPP, NPV and IRR values.

\section{Measured wind data}

Wind speed measurements have been performed in Cumra, Turkey since 2006 with the help of a wind pole in the region. Five anemometers are installed at various heights on the wind pole and the wind speed data measured at $80 \mathrm{~m}$ height in 2013 are used in the present study. Monthly mean wind speeds are shown in Figure 1.

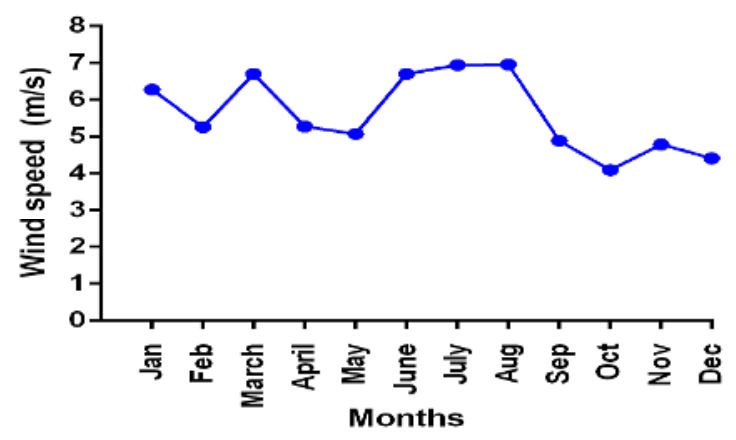

Figure 1. Monthly mean wind speeds

As seen from Fig. 1, mean wind speed is higher in summer months compared to other months and highest mean wind speed is obtained in August. Wind rose plot depicting wind speed frequency and energy potential according to the wind direction is given in Fig. 2.
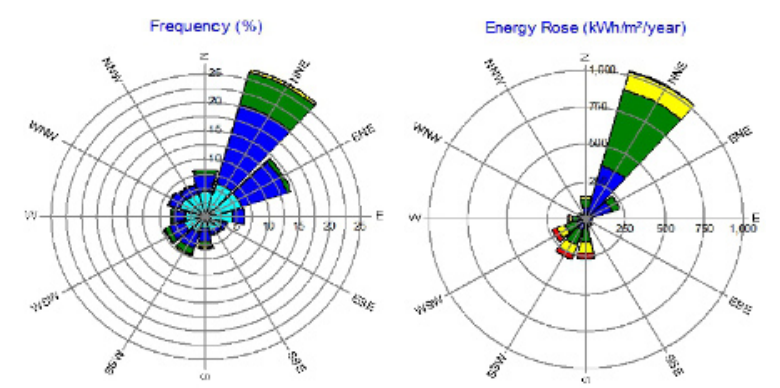

Figure 2. Wind speed frequencies and energy potential

\section{Selected wind turbines}

Six commercial wind turbines are selected to predict annual energy production and perform economic analysis. Total installed power is assumed to be $6 \mathrm{MW}$ according to the power requirement in the region and wind turbines are selected considering this value. Characteristics of wind turbines are given in Table 1.
Table 1. Characteristics of the selected turbines

\begin{tabular}{|l|l|l|l|l|}
\hline $\begin{array}{l}\text { Wind } \\
\text { turbines }\end{array}$ & $\begin{array}{l}\text { Cut-in } \\
\text { WS } \\
(\mathbf{m} / \mathbf{s})\end{array}$ & $\begin{array}{l}\text { Cut-out } \\
\text { WS } \\
(\mathbf{m} / \mathbf{s})\end{array}$ & $\begin{array}{l}\text { Rated } \\
\text { Power } \\
(\mathbf{k W})\end{array}$ & $\begin{array}{l}\text { Rotor } \\
\text { diameter } \\
(\mathbf{m})\end{array}$ \\
\hline WT -1 & 3 & 25 & 3000 & 115 \\
\hline WT -2 & 3 & 21 & 3000 & 122 \\
\hline WT - 3 & 3 & 22 & 2000 & 100 \\
\hline WT - 4 & 3 & 25 & 1500 & 100 \\
\hline WT - 5 & 3 & 24 & 2000 & 100 \\
\hline WT - 6 & 3 & 25 & 1500 & 86 \\
\hline
\end{tabular}

\section{Calculation Methodology}

Capacity factor is the ratio of annual output to potential output, and it is calculated using the Eq. 1 where $\mathrm{P}_{\text {annual }}$ is the annual energy production (MW) and $\mathrm{P}_{\text {potential }}$ is the annual potential energy production in full capacity (MW).

$$
\mathrm{C}_{\mathrm{p}}=\mathrm{P}_{\text {annual }} / \mathrm{P}_{\text {potential }}
$$

Unit cost is calculated using Eq. 2. In this equation, $E_{w t}$ is the cost of the wind turbine $(€)$ and $n$ is the lifespan (year) of the project.

$$
\mathrm{UC}=\mathrm{E}_{\mathrm{wt}} /\left(\mathrm{P}_{\mathrm{annual}} \mathrm{X} \mathrm{n}\right)
$$

Basic payback period is the ratio of total expenditures, $\mathrm{E}_{\text {total }}(€)$ to annual savings $(€)$.

$$
\mathrm{BPP}=\mathrm{E}_{\mathrm{total}} / \mathrm{AS}
$$

Total expenditures include wind turbine cost, total operation and maintenance (O\&M) cost in the lifespan period, foundation, transmission line and other costs. It is given in Ref. [16] that the O\&M costs are approximately 0.3-0.4 $\mathrm{c} € / \mathrm{kWh}$ during the first two years and approximately $0.6-0.7 \quad \mathrm{c} € / \mathrm{kWh}$ after six years for wind turbines. In our calculations, we considered the value $0.5 \mathrm{c} € / \mathrm{kWh}$ for wind turbines. Foundation, transmission line and other costs are taken as $20 \%$ of the wind turbine price.

Net present value (NPV) is calculated by discounting all future income and expenditure flows to the present with Eq. 4 [9].

$$
\mathrm{NPV}=\sum[(\mathrm{B}-\mathrm{C}) /(1+\mathrm{r}) \mathrm{n}]
$$

Where, $\mathrm{B}$ is the benefit, $\mathrm{C}$ is the cost, $\mathrm{r}$ is the discount rate and $\mathrm{n}$ is lifecycle year of the project. In this study, the project lifespan was taken as 25 years for the analysis and the overall annual interest rate (r) is assumed to be $2.5 \%$. Salvage cost was not taken into account which was estimated to be equal to the disassembly cost of the wind power system components at the end of the project lifespan. IRR is the rate, which would make NPV value zero and it can be calculated with Eq. 5, where the parameters are same as the ones of NPV [9].

$$
\sum[\mathrm{B} /(1+\mathrm{r}) \mathrm{n}]=\sum[\mathrm{C} /(1+\mathrm{r}) \mathrm{n}]
$$


Table 2. Annual electricity productions, capacity factors and unit prices of selected wind turbines

\begin{tabular}{|l|l|l|l|l|l|l|}
\hline & WT - 1 & WT - 2 & WT - 3 & WT - 4 & WT - 5 & WT - 6 \\
\hline Rated Power (MW) & $3 \mathrm{MW}$ & $3 \mathrm{MW}$ & $2 \mathrm{MW}$ & $1.5 \mathrm{MW}$ & $2 \mathrm{MW}$ & $1.5 \mathrm{MW}$ \\
\hline WT Cost* (€) & $4,050,000$ & $3,350,000$ & $2,175,000$ & $2,525,00$ & $2,575,000$ & $1,875,000$ \\
\hline Number of WT & 2 & 2 & 3 & 4 & 3 & 4 \\
\hline $\begin{array}{l}\text { Foundation, Transmission line and } \\
\text { other costs (€) }\end{array}$ & $1,620,000$ & $1,340,000$ & $1,305,000$ & $2,020,000$ & $1,545,000$ & $1,500,000$ \\
\hline O\&M costs for 25 years (€) & $1,769,125$ & $1,557,500$ & $1,776,500$ & $2,135,875$ & $1,816,125$ & $1,642,625$ \\
\hline Total Cost(€) & $11,489,125$ & $9,597,500$ & $9,606,500$ & $14,255,875$ & $11,086,125$ & $10,642,625$ \\
\hline $\begin{array}{l}\text { Annual Electricity Production } \\
\text { (MWh) }\end{array}$ & 14,153 & 12,460 & 14,212 & 17,087 & 14,529 & 13,141 \\
\hline $\begin{array}{l}\text { Total generated electricity in 25 } \\
\text { years (MWh) }\end{array}$ & 353,825 & 311,500 & 355,300 & 427,175 & 363,225 & 328,525 \\
\hline Unit cost of the electricity (€/kWh) & 0.0325 & 0.0308 & 0.0270 & 0.0334 & 0.0305 & 0.0324 \\
\hline Capacity Factor, Cp (\%) & 26.9 & 23.7 & 27 & 32.5 & 27.6 & 25 \\
\hline
\end{tabular}

*Cost of one wind turbine including its installation cost.

Table 3. Economic feasibility analysis results

\begin{tabular}{|l|l|l|l|l|l|l|}
\hline Turbine type & WT - 1 & WT - 2 & WT - 3 & WT - 4 & WT - 5 & WT - 6 \\
\hline Investment cost $\mathbf{1}^{\mathbf{~}(\boldsymbol{)})}$ & 9720000 & 8040000 & 7830000 & 12120000 & 9270000 \\
\hline $\begin{array}{l}\text { Annual energy production } \\
\text { (MWh/year) }\end{array}$ & 14153 & 12460 & 14212 & 17087 & 14000000 \\
\hline Annual cost saving (€/year) & 1556830 & 1370600 & 1563320 & 1879570 & 13141 \\
\hline $\begin{array}{l}\text { Operation and maintenance } \\
\text { cost (€/year) }\end{array}$ & 70765 & 62300 & 71060 & 85435 & 1598190 \\
\hline $\begin{array}{l}\text { Net annual cost saving } \\
\text { (€/year) }\end{array}$ & 1486065 & 1308300 & 1492260 & 1794135 & 72645 \\
\hline Basic payback period (years) & 6.54 & 6.15 & 5.25 & 6.76 & 1525545 \\
\hline NPV (€) & $17,659,820$ & $16,064,611$ & $19,663,960$ & $20,935,819$ & 1379805 \\
\hline IRR (\%) & 14.8 & 15.9 & 18.8 & 14.3 & 6.08 \\
\hline
\end{tabular}

${ }^{1}$ Investment cost includes installation and other additional costs except O\&M costs.

${ }^{2}$ Net annual cost saving is calculated by subtracting yearly O\&M costs from annual cost saving.

\section{Results}

The power outputs, capacity factors and unit prices of the selected turbines are given in Table 2. As mentioned before, total installed power is assumed to be $6 \mathrm{MW}$. According to the Table 2, capacity factors and unit prices change between $25-32.5 \%$ and $0,027-$ $0,0325 € / \mathrm{kWh}$, respectively. Although WT -4 has the highest capacity factor, WT -3 has the best unit price because of its cheaper price. Economic feasibility analysis results are presented in Table 3. All the options have basic payback periods that change between 5,25 and 6,54 years, and the most feasible one is found to be the WT -3 .

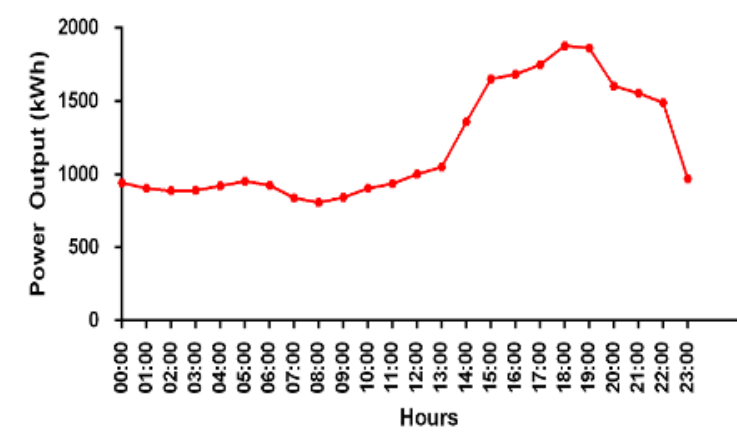

Figure 3. Hourly mean power production

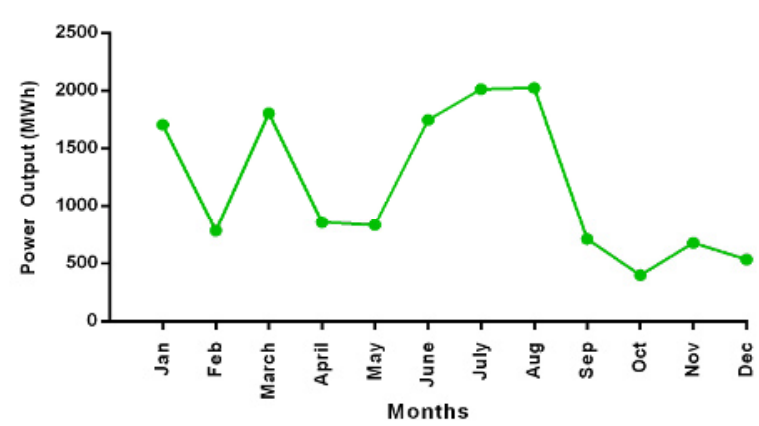

Figure 4. Monthly power production

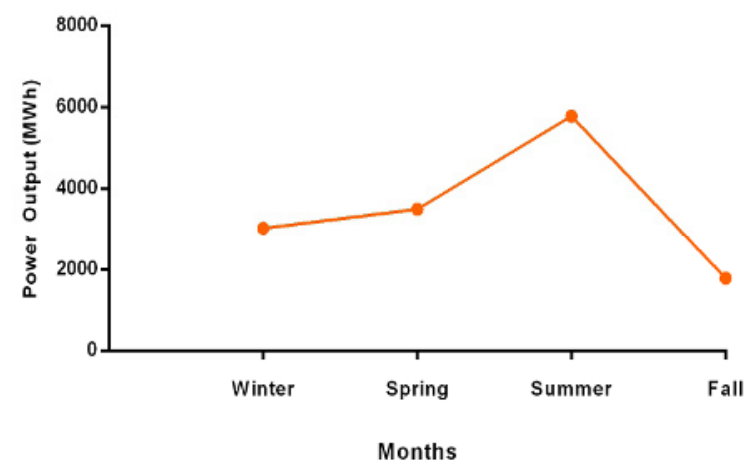

Figure 5. Seasonal power production 
Hourly mean, monthly and seasonal power productions are simulated for the most feasible option, the one including three of WT $-3 \mathrm{~s}$. Hourly, monthly and seasonal mean power productions are presented in Fig. 3, 4 and 5, respectively. As it is can be seen from the figures, maximum power productions are obtained during evening hours on a daily basis and during summer months on a monthly basis.

\section{Conclusion}

In the present study, feasibility of a wind power plant in a low rated wind speed region is investigated and it is found out that it can also be feasible to install wind power plants in low rated wind speed regions. A good capacity factor that is about $32 \%$ is obtained for a commercial wind turbine, however, it was not the most feasible option because of the higher price. A reasonable basic payback period, 5.25 years, is obtained in the region where the average wind speed is under $6 \mathrm{~m} / \mathrm{s}$ at $80 \mathrm{~m}$ height. This shows that the more the wind turbine technology enhances, the more feasible wind power plants will become in low rated wind speed regions in the future. Simulation results show that maximum power output from the wind power plant is obtained during the times when maximum energy consumption levels are reached.

\section{Acknowledgement}

Authors would like to thank to Alibeyhuyugu Irrigation Cooperation for providing the data.

\section{References}

1. GWEC- Global Wind Energy Council, Global Wind Power Statistics (2015), available online at : http://www.gwec.net/wpcontent/uploads/vip/GWEC-PRstats2015_LR_corrected.pdf.

2. B. Ozerdèm, S. Ozer, M. Tosun, Feasibility study of wind farms: A case study for Izmir, Turkey J. Wind Eng. Ind. Aerodyn. 94, 10 (2006).

3. A. Demirbas, Competition Potential of Wind Power Plants, Energy Sources 27, 7 (2005).

4. S. M. Shaahid, L.M. Al-Hadhrami, M.K. Rahman, Economic feasibility of development of wind power plants in coastal locations of Saudi Arabia A review, Renewable Sustainable Energy Rev. 19 (2013).

5. T. Khatib, K. Sopian, M. Z. Ibrahim, Assessment of electricity generation by wind power in nine costal sites in Malaysia, Renewable Sustainable Energy Rev. (2012).

6. A. N. Celik, A Techno-Economic Analysis of Wind Energy in Southern Turkey Int. J. Green Energy 4, 3 (2007).

7. A. Mostafaeipour, A. Sedaghat, A. A. Dehghan-Niri, V. Kalantar, Wind energy feasibility study for city of Shahrbabak in Iran, Renewable Sustainable Energy Rev. 15, 6 (2011).

8. T. Blackler, M.T. Iqbal, Pre-feasibility study of wind power generation in Holyrood, Newfoundland, Renewable Energy 31, 4 (2006).

9. M.S. Genç, M. Gökçek, Evaluation of Wind Characteristics and Energy Potential in Kayseri, Turkey, J. Energy Eng. 135, 2 (2009).

10. F. Kose, M.N. Kaya, Analysis on meeting the electric energy demand of an active plant with a wind-hydro hybrid power station in Konya, Turkey: Konya water treatment plant Renewable Energy 55 (2013).

11. F. Kose, M. H. Aksoy, M. Ozgoren, An assessment of wind energy potential to meet electricity demand and economic feasibility in Konya, Turkey, International Journal of Green Energy 11 (2014).

12. M. R. Nouni, S. C. Mullick, T. C. Kandpal, Technoeconomics of small wind electric generator projects for decentralized power supply in India, Energy Policy 35 (2007).

13. F. Kose, M.H. Aksoy, M. Ozgoren, "Economic Feasibility of Wind Energy Potential in Konya, Turkey", International Scientific Conference, UNITECH09, Proceedings (2009) Gabrovo, Bulgaria.

14. S.M. Shaahid, L.M. Al-Hadhrami, M.K. Rahman, Economic feasibility of development of wind power plants in coastal locations of Saudi Arabia A review, Renewable Sustainable Energy Rev. 19, (2013).

15. R. Majumder, I. Mukherjee, B. Tudu and D. Paul, Review on feasibility of wind energy potential for India, Non Conventional Energy (ICONCE), 1st International Conference on, Kalyani (2014).

16. The European Wind Energy Association (EWEA), Wind energy 2 (2011). 